\title{
A LIBERDADE DE EXPRESSÃO E A APLICAÇÃO DE SANÇÕES PENAIS COMO MEDIDAS ULTERIORES NO SISTEMA INTERAMERICANO DE DIREITOS HUMANOS
}

\section{FREE SPEECH AND THE APPLICATION OF CRIMINAL PENALTIES AS FURTHER MEASURES IN INTER-AMERICAN SYSTEM OF HUMAN RIGHTS}

\author{
${ }^{1}$ Anna Laura Maneschy Fadel \\ ${ }^{2}$ Natalia Mascarenhas Simões Bentes
}

\section{RESUMO}

O presente artigo parte do pressuposto de que a Liberdade de Expressão não é absoluta. Portando, admite-se a aplicação de medidas ulteriores quando este direito desrespeitar a honra e boa fama alheia. Todavia, demanda-se se a utilização da sanção penal como instrumento de punição é um meio idôneo e compatível com os ditames do Sistema Interamericano de proteção dos Direitos Humanos. Destarte, almeja-se encontrar a hermenêutica aplicada no histórico jurisprudencial, a fim de estabelecer os padrões fixados pela Corte IDH quanto à matéria

Palavras-chave: Direito internacional público, Liberdade de expressão, Medidas ulteriores

\begin{abstract}
This article assumes that freedom of expression is not absolute. Therefore, it is assumed the application of further measures when this right disrespects the honor and good reputation of others. However, it demands the use of criminal sanctions as punishment instrument is the best means and compatible with the dictates of the inter-American system of protection of human rights. Thus, it aimed to find hermeneutics applied to the jurisprudential history in order to establish the standards set by the the Court and the Comission.
\end{abstract}

Keywords: International public law, Free speech, Further measures

\footnotetext{
${ }^{1}$ Mestranda em Direito, Políticas Públicas e Desenvolvimento Regional do Centro Universitário do Estado do Pará- CESUPA, Pará, PA. (Brasil). E-mail: annalauramaneschy@gmail.com

${ }^{2}$ Doutoranda em Direito. Pela Universidade de Coimbra - UC (Portugal). Professora do Centro Universitário do Estado do Pará, CESUPA, Pará, PA.(Brasil) E-mail: natalia.bentes@cesupa.br
} 


\section{INTRODUÇÃO}

A previsão da Liberdade de Expressão $^{1}$ na Convenção Americana possui caráter extensivo, a qual abrange não apenas o direito de manifestar o seu próprio pensamento, mas, também, o de transmiti-lo aos demais. Isto é reafirmado ao longo do histórico jurisprudencial, o qual compreende como instrumento intimamente ligado ao modelo democrático, por ser responsável a propiciar o acesso à informação a todos os cidadãos.

O tratamento do conteúdo do art. 13 pela Corte Interamericana de Direitos Humanos (Corte IDH) era bastante restrito, já que poucos eram os casos que versavam sobre a direta violação da Liberdade de Expressão. Dessa maneira, a única manifestação específica acerca deste foi a Opinião Consultiva $\mathrm{n}^{\circ} 5$ (OC-5), dado que havia sido requisitado um parecer consultivo sobre Liberdade de Expressão e o exercício do jornalismo, pela Costa Rica, em 1985 (BERTONI, 2011).

Este documento foi um importante instrumento interpretativo para as decisões que vieram a ser proferidas pela Corte IDH, em matéria de Liberdade de expressão. Podem-se citar como algumas características marcantes da supramencionada Opinião Consultiva: a possibilidade de impor responsabilidades ulteriores (mesmo que de forma geral); a proibição de restrição por meios indiretos, a possibilidade de censura prévia; proibição de qualquer tipo de apologia discriminatória e a perspectiva de um direito de caráter dúplice (individual e coletivo) (BERTONI, 2011).

Todavia, tratando-se das responsabilidades ulteriores, foco da presente discussão, percebe-se que a Liberdade de Expressão não é um direito absoluto. Portanto, esta garantia pode estar sujeita a condições e restrições quando interferir em direitos também previstos na Convenção. Assim, o art. 13.2 prevê a possibilidade de supressão, quando houver um

\footnotetext{
${ }^{1}$ Artigo 13 LIBERDADE DE PENSAMENTO E DE EXPRESSÃO

1. Toda pessoa tem direito à liberdade de pensamento e de expressão. Esse direito compreende a liberdade de buscar, receber e difundir informações e ideias de toda natureza, sem consideração de fronteiras, verbalmente ou por escrito, ou em forma impressa ou artística, ou por qualquer outro processo de sua escolha.

2. O exercício do direito previsto no inciso precedente não pode estar sujeito à censura prévia, mas a responsabilidades ulteriores, que devem ser expressamente fixadas pela lei e ser necessárias para assegurar: o respeito aos direitos ou à reputação das demais pessoas; ou a proteção da segurança nacional, da ordem pública, ou da saúde ou da moral públicas.

3. Não se pode restringir o direito de expressão por vias ou meios indiretos, tais como o abuso de controles oficiais ou particulares de papel de imprensa, de frequências radioelétricas ou de equipamentos e aparelhos usados na difusão de informação, nem por quaisquer outros meios destinados a obstar a comunicação e a circulação de ideias e opiniões.
} 
exercício abusivo desse direito, inclusive para resguardar a reputação dos demais (CORTE IDH, Herrera Ulloa vs. Costa Rica, §146).

2. O exercício do direito previsto no inciso precedente não pode estar sujeito à censura prévia, exceto no caso de responsabilidades ulteriores, as quais devem estar expressamente fixadas por lei e serem necessárias para assegurar:

a) O respeito aos direitos da reputação dos demais ou;

b) Proteger a segurança nacional, a ordem pública, a saúde ou a moral pública.

A partir dessa preposição, apreendem-se três conclusões básicas, estas são: a de que o exercício da Liberdade de Expressão, apenas pode ser restringido se esta responsabilidade está prevista em lei, se for necessária e que esta necessidade esteja pautada: no respeito dos direito á reputação dos demais cidadãos, proteção da segurança nacional, ordem, saúde ou moral pública.

Logo, estas restrições possuem caráter excepcional e não devem impedir o seu exercício de forma arbitrária, apenas quando for estritamente necessário. Isto é, estas não poderão converter-se em meios diretos ou indiretos de censura prévia (CORTE IDH, Herrera Ulloa vs. Costa Rica, §146). Os países que ratificaram a competência contenciosa da Convenção Americana, os quais se submetem à jurisdição da Corte Interamericana, são latino-americanos. Portanto, por estar em um recente contexto democrático, a relação com a Liberdade de Expressão ainda se demonstra conturbada.

Dessa maneira, de certa forma, a Corte Interamericana e sua jurisprudência, por consequência, tenta, verdadeiramente, ensiná-los a lidar com o referido direito e ditar aquilo o que é aceitável e compatível com uma Democracia. Entretanto, o ideal de que a proteção dos direitos humanos é hierarquicamente superior, devendo sempre ser salvaguardada, ainda se demonstra conflituoso em face da Soberania dos Estados e os limites de deliberação dos mesmos. Nesse sentido, a Corte Europeia, por exemplo, aplica a Teoria da Margem de Apreciação $^{2}$, com a finalidade de conciliar o poder de decisão dos Estados e a competência jurisdicional das Cortes Internacionais. Ademais, salienta-se que a referida teoria afirma que os Estados membros estariam mais aptos a proferir uma decisão, em função do Princípio da Especialidade.

No entanto, deve-se ter em mente que a Corte Europeia convive em uma realidade diversa da Corte Interamericana. Sabe-se que nos países europeus há diferenças culturais,

\footnotetext{
${ }^{2}$ Significa dizer que uma margem de apreciação, ou área de julgamento discricionário é permitida aos Estados quando estes julgam existir uma necessidade social e a natureza de uma resposta apropriada. A noção da "margem de apreciação" baseia-se no fato de que as autoridades nacionais estão numa posição melhor do que um tribunal internacional para julgar o que é necessário de acordo com as condições locais. Em direito internacional público, ela oferece uma maneira de mediar a tensão entre a soberania estatal em relação as instituições internacionais e a necessidade de universalização dos patamares dos direitos humanos (FELDMAN, 2002 apud CORREA, 2002).
} 
econômicas e mesmo religiosas que não podem ser afastadas. Por isso, a universalização dos direitos humanos aparenta ser mais problemática que no contexto americano.

Enfatizar uma realidade "americana" nem mesmo parece adequado, tendo em vista a realidade fática da aplicação das decisões da Corte Interamericana. O mais correto, aparentemente, seria denominar de contexto "latino-americano". E nesse contexto, a proximidade cultural e histórica é perceptível, principalmente, quanto ao modelo político vivenciado no século XX, os regimes de força. Por esse motivo, a Corte Interamericana de Direitos Humanos possui um papel pedagógico dentro das Democracias instauradas, bem como nos ordenamentos jurídicos internos, em especial ao se tratar de Liberdade de Expressão, como ressaltado anteriormente.

Destarte, o presente artigo discute se a aplicação de sanções penais como medidas ulteriores, quando violado o direito à Honra de funcionários públicos, resguardado no art. 11 da Convenção, é plenamente válida e compatível com a Convenção Americana, em relação aos crimes de calúnia, injúria, difamação e desacato.

Outrossim, serão analisadas cronologicamente as sentenças que versem sobre o exercício da Liberdade de Expressão, nas quais as vítimas tenham sido punidas pela esfera criminal, com o desiderato de averiguar se há padrões nos julgados, bem como quais os critérios adotados pela Corte IDH.

\section{A JURISPRUDÊNCIA DA CORTE INTERAMERICANA QUANTO À POSSIBILIDADE DE APLICAÇÃO DA SANÇÃO PENAL COMO MEDIDAS ULTERIORES}

O primeiro caso decidido acerca da problemática pela Corte IDH foi o Herrera Ulloa vs. Costa Rica, em 05 de janeiro de 2004, o qual versa sobre o procedimento e sanção penal e civil imposta ao jornalista Mauricio Herrera Ulloa e a sanção civil imposta ao sr. Fernán Vargas Rohrmoser, representante legal do meio de comunicação social "La Nácion" da Costa Rica, como consequência de haverem publicado diversos artigos que reproduziam, parcialmente, informações de alguns jornais europeus, referentes à supostas atividades ilícitas praticas pelo sr. Félix Pzedborski, diplomata costarriquense, sobre negociações e vendas de helicópteros italianos de combate ao Estado da Bélgica. À época dos fatos, o sr. Pzedborski era representante da Costa Rica diante da Organização de Energia Atômica na Áustria, como cônsul. Dessa maneira, quatro desses artigos foram objeto de demandas pelo sr. Pzedborski, as quais renderam condenações civis e penais (pelo crime de difamação) ao sr. Herrera Ulloa e o meio de comunicação "La Nácion”, como responsável civil solidário. 
Com efeito, destaca-se que a decisão elencada pela Corte, dividiu-se em quatro momentos: 1) conteúdo da liberdade de expressão; 2) a liberdade de expressão em uma sociedade democrática; 3) o rol dos meios de comunicação e a relação do jornalismo com a liberdade de expressão e 4) restrições permitidas à liberdade de expressão em uma sociedade democrática.

Inicialmente, destaca-se que o direito à Liberdade de Expressão possui duas dimensões distintas: uma individual e uma coletiva. Logo, os indivíduos não possuem apenas o direito de expressar seu próprio pensamento, mas a liberdade de buscar, receber e difundir informações e ideias de toda índole (CORTE IDH, Herrera Ulloa vs. Costa Rica, §108).

Trazendo à baila outro contexto importante a ser analisado é a relação da Liberdade de Expressão com a Democracia, faz-se mister suscitar o entendimento:

\begin{abstract}
A liberdade de expressão é uma pedra angular para a própria existência de uma sociedade democrática. É indispensável para a formação da opinião pública (...) É, em suma, uma condição para que a comunidade, no exercício das suas opções, esteja suficientemente informada. Assim, é possível afirmar que uma sociedade que não está bem informada não é plenamente livre.
\end{abstract}

Apesar de existir duas dimensões da Liberdade de Expressão, sublinha-se que estas são igualmente importantes e independentes. Cabe aos Estados-membros, portanto, garanti-las de maneira plena e concomitante $\left(\mathrm{CIDH}, 2010, \S 16^{\circ}\right)$. Isto posto, não pode haver supressão de uma dessas dimensões sobre o argumento de proteção à outra (CIDH, 2010, §17²).

A intrínseca ligação entre o Regime Democrático e a Liberdade de Expressão é a de que caso esse direito pereça, põe-se em risco a vigência de todos os demais valores e princípios estruturantes de uma sociedade democrática. Por conseguinte, a possibilidade de expressar ideias livremente é fundamental para a plena existência dos demais direitos. Sem Liberdade de Expressão e Informação, não há o exercício de uma democracia plena. Isto pode ser comprovado, até mesmo, pela história de governos totalitários no hemisfério sul, nos quais a inibição da expressão (particular ou coletiva) incidiu na violação de demais direitos, como: a vida e a propriedade (BERTONI, 2011). Nesta linha de pensamento, quando se restringe ilegalmente a liberdade de um indivíduo se expressar, não é apenas o direito deste que está sendo passível de violação, mas o direito de coletivo de conhecer a expressão do pensamento alheio $^{3}$. Portanto, compreende-se que a Liberdade de Expressão é "uma pedra angular" 4 para a existência de uma ordem democrática.

\footnotetext{
${ }^{3}$ CORTE IDH. La cole

giación obligatoria de periodistas (arts. 13 y 29 de la Convención Americana sobre Derechos Humanos), Opinión Consultiva 5/85 (en adelante OC-5 o La colegiación obligatoria) del 13 de noviembre de 1985, $\begin{array}{lllll}\text { Serie } & \text { A, } & \text { No. } & \text { P. } & \text { Parr. }\end{array}$
} 
Em consonância a esse ideal, os Estados-membros da Convenção devem primar por uma sociedade baseada na pluralidade e na diversidade, para que os debates públicos propiciem a participação de diferentes correntes, impulsionando o debate (CIDH, 2010, $\S 225^{\circ}$ ). Deve-se, conseguintemente, garantir a participação de diversos grupos, de forma igualitária, no processo de comunicação $\left(\mathrm{CIDH}, 2010, \S 226^{\circ}\right)$, independente de que as eventuais críticas sejam contra a própria figura do Estado. Logo, é indispensável para a formação e consolidação da opinião pública e “conditio sine qua non” para os partidos políticos, sindicatos e sociedades civis e culturais em geral (TORRIJO, 2002). Isto porque são estes, em regra geral, capazes de expressar coletivamente os interesses sociais.

Destarte, ao se analisar o papel do jornalismo em uma sociedade democrática, é válido sublinhar dois pontos principais. Primeiramente, de que os jornalistas não podem ser visto apenas como um conceito técnico, mas como responsáveis pela comunicação social (CORTE IDH, Herrera Ulloa vs. Costa Rica, §118). E, além deste, a Importância de permitir que os jornalistas possuam proteção para trabalhar e ter independência necessária para realizar suas funções, já que são eles que mantêm informada a sociedade, requisito indispensável para que se alcance o gozo de uma liberdade plena (CORTE IDH, Herrera Ulloa vs. Costa Rica, $\S 119)$.

Desta feita, a partir dos parâmetros previstos na Opinião Consultiva $n^{\circ} 5$ (OC-5), importante instrumento interpretativo para as decisões proferidas pela Corte IDH, em matéria de Liberdade de Expressão. Podem-se citar como algumas características marcantes da supramencionada Opinião Consultiva: a possibilidade de impor responsabilidades ulteriores (mesmo que de forma geral); a proibição de restrição por meios indiretos, a possibilidade de censura prévia; proibição de qualquer tipo de apologia discriminatória e a perspectiva de um direito de caráter dúplice (individual e coletivo) (BERTONI, 2011).

Assim, tratando-se das responsabilidades ulteriores, podem-se apreender os limites impostos pelo entendimento da Corte, quais sejam:

1. Toda pessoa tem o direito à liberdade de pensamento e de expressão. Este direito compreende a liberdade de buscar, receber e difundir informações e ideias de toda índole, sem considerar fronteiras, seja oralmente, por escrito, em forma impressa, artística ou por qualquer outro modo de sua escolha.

2. O exercício do direito previsto no inciso precedente não pode estar sujeito à censura prévia, exceto no caso de responsabilidades ulteriores, as quais devem estar expressamente fixadas por lei e serem necessárias para assegurar:

a) O respeito aos direitos da reputação dos demais ou;

b) Proteger a segurança nacional, a ordem pública, a saúde ou a moral pública

4 , La colegiación obligatoria, de periodistas (arts. 13 y 29 de la Convención Americana sobre Derechos Humanos), Opinión Consultiva 5/85 (en adelante OC-5 o La colegiación obligatoria) del 13 de noviembre de 1985, Serie A, No. 5, párr. 70. 
A partir dessa preposição, compreendem-se três conclusões básicas, estas são: a de que o exercício da Liberdade de Expressão, apenas pode ser restringido se esta responsabilidade está prevista em lei (não devem apenas estar pautadas em leis, mas essas leis devem preponderar o interesse público e permitir o gozo de demais direitos), se for necessária e que esta necessidade esteja pautada: no respeito dos direito à reputação dos demais cidadãos, proteção da segurança nacional, ordem, saúde ou moral pública. Em outros termos, que sejam estritamente necessárias em uma sociedade democrática (CORTE IDH, Herrera Ulloa vs. Costa Rica, §59).

Nesse contexto, é lógico e apropriado que as expressões concernentes a funcionários públicos e outras pessoas que exerçam funções de natureza pública devem gozar, nos termos do art. 13.2 da Convenção, de uma margem de abertura a um debate amplo a respeito de assuntos de interesse público, o qual é essencial para o funcionamento de um sistema verdadeiramente democrático. Isto não significa, de forma alguma, que a honra dos funcionários públicos ou das pessoas públicas não devam ser juridicamente protegidas, mas devem estar de acordo com os princípios de um pluralismo democrático (CORTE IDH, Herrera Ulloa vs. Costa Rica, §128).

Desta forma, as pessoas públicas possuem uma esfera diferenciada de proteção na qualidade sujeito. Isto porque os atos por eles praticados são de interesse público. Portanto, as pessoas que influem em questões de interesse público estão expostas (voluntariamente) a uma critica pública mais exigente. Por consequência, estão mais suscetíveis a sofrer críticas, já que seus atos saem do domínio da esfera privada para entrelaçar-se na esfera do debate público (CORTE IDH, Herrera Ulloa vs. Costa Rica, §129).

Portanto, este é um quesito paradigmático acerca do debate travado no presente artigo, visto que se possibilita uma flexibilização quanto à possibilidade de violação à honra de funcionários públicos. Consequentemente, considera-se o embrião de toda a questão proposta, em função de analisar se as medidas ulteriores, especialmente em matéria punitiva criminal, e sua compatibilidade com uma sociedade democrática.

Em seguida, o caso que versa sobre a mesma matéria, com sentença de 31 de janeiro de 2004, chama-se Ricardo Canese vs. Paraguai. Ricardo Canese foi processado e condenado pelo crime de difamação como consequência das alegações feitas em agosto de 2012, quando era candidato à presidente no Paraguai. As declarações de Canese contestavam a integridade e idoneidade do outro candidato presidenciável, Juan Carlos Wasmosy, quando era então presidente-diretor da CONEMPA (Consórcio de Empresas construtoras paraguaias), empresa 
que participou da construção do complexo hidrelétrico de Itaipu e de suas ligações com o exditador paraguaio Stroessner. Tais alegações tiveram como embasamento queixas feitas pelos demais sócios da CONEMPA, que não haviam sido citados nos escritos por Canese.

Destarte, em virtude de tais publicações, em 22 de março de 1994, foi condenado pelas tais e em 04 de novembro de 1997 teve ratificação da sentença condenatória proferida pelo juízo de piso. Assim, foi condenado pelo crime de difamação, com pena de 2 meses de penitenciária e uma multa de 2.909 .000 guaranis. Ademais, como consequência da condenação penal, o sr. Canese foi submetido a uma restrição permanente de sair do país, por mais de 8 anos e 4 meses. Em 11 de dezembro de 2002, com posterior interposição da demanda na Corte, a Suprema Corte de Justiça do Paraguai acolheu o pedido revisional feito pelo sr. Canese, o qual anulou as sentenças condenatórias (a esfera civil e penal) contra sua pessoa.

A Corte observou que as declarações pelas quais o sr. Canese foi denunciado se deram durante o debate da campanha eleitoral à Presidência da República, em um contexto de transição para a democracia, já que por 35 anos (e até 1989), o país tinha como forma de governo a ditadura. Dessa maneira, a eleição presidencial na qual o sr. Canese concorreu, foi um importante marco, isto porque o Paraguai passava por um processo de redemocratização. Logo, suas declarações foram de extrema importância para o fomento do debate democrático (CORTE IDH, Ricardo Canese vs. Paraguai, §87).

Outrossim, já havia sido estabelecido que é lógico e apropriado que as informações concernentes a funcionários públicos ou outras pessoas que exerçam funções de uma natureza pública devem gozar, de acordo com o art. 13.2 da Convenção, uma margem de abertura maior aos debates que versem sobre assuntos de interesse público, os quais são essenciais para o funcionamento de um sistema democrático. Este é o mesmo critério que se aplica a respeito das opiniões e declarações de interesses públicos que versem sobre uma pessoa que concorre à Presidência da República, a qual se submete voluntariamente às críticas públicas.

Logo, como se tratam de assuntos de interesse público dos quais a sociedade tem um interesse legítimo de se manter informada, de conhecer sobre o funcionamento do Estado, afeta-se, portanto, os direitos em gerais, os quais acarretam consequências importantes. Como foi estabelecido, não dúvida de que as declarações feitas pelo sr. Canese, sem relação a empresa CONEMPA, são tidas como assunto de interesse público (CORTE IDH, Ricardo Canese vs. Paraguai, §98).

Dessa maneira, compreende-se que deveria ter sido ponderado pelo Judiciário do 
Paraguai no processo contra o sr. Canese, que as declarações encontravam-se em um contexto de uma campanha eleitoral, a Presidência da República do país. Consequentemente, tratava-se de assuntos de interesse público, circunstância na qual as opiniões e críticas se emitem de maneira mais aberta, intensa e dinâmica, de acordo com os princípios do pluralismo democrático. No presente caso, o julgador deveria sopesar o respeito dos direitos a reputação dos demais, com o valor de uma sociedade democrática, o debate aberto sobre temas de interesse ou preocupação pública (CORTE IDH, Ricardo Canese vs. Paraguai, §105).

Conclui-se, acerca do caso Canese, que no processo penal e na consequente condenação imposta ao sr. Canese, durante mais de oito anos (como a restrição de sair do país), sustenta-se que as medidas aplicadas como restrição ao direito da Liberdade de Expressão constituíram uma sanção desnecessária e excessiva, visto que em um contexto democrático, tais sanções impediram que se propagasse um debate aberto sobre temas relevantes a toda a sociedade.

Assim, tendo em vista os fatos suscitados, não existia um interesse social imperativo que justificasse a sanção penal, pois se limitou desproporcionalmente a Liberdade de pensamento e expressão da vítima, além do fato destas declarações serem questões de interesse público. Logo, constitui-se uma restrição ou limitação excessiva em uma sociedade democrática, incompatível com o art. 13 da Convenção Americana (CORTE IDH, Ricardo Canese vs. Paraguai, §106).

Em linha similar, apresenta-se a demanda Paramara Iribarne vs. Chile, julgada em 22 de novembro de 2005, a qual se refere à proibição, em março de 1993, da publicação do livro do sr. Humberto Antonio Palarama Iribarne, intitulado "Ética e Serviços de Inteligência”. Abordava-se na obra aspectos relacionados com a inteligência militar e a necessidade de adequá-la a certos parâmetros éticos, sublinha-se de que o mesmo exercia funções da Marinha chilena. Os exemplares do livro, os originais e o disco rígido que possuía a cópia original foram apreendidos na sede da empresa, na qual iriam imprimir os livros (assim como, a suposta eliminação da íntegra do texto que estava na casa do senhor Iribarne). Ademais, foi retirado da Marinha chilena, já que no período dos fatos, era funcionário civil da mesma, na cidade de Punta Arenas. Além do exposto, ressalta-se que o sr. Iribarne foi processado e condenado pelos crimes de desobediência e, devido a conferência de impressa, desacato (CORTE IDH, Iribarne vs. Chile, §2).

O livro do sr. Iribarne, assim como suas declarações, foram publicadas em meios de comunicação, implicando, portanto, no exercício da liberdade de pensamento e de expressão, 
mediante a difusão de seus pensamentos e ideias sobre aspectos relacionados à necessidade de que o "pessoal de inteligência", com vistas de evitar violações aos direitos humanos, adotando uma conduta ética mínima. Ademais, possibilitou que manifestasse suas opiniões sobre o tratamento que recebeu por parte das autoridades, as quais ele e sua família estavam submetidos (CORTE IDH, Iribarne vs. Chile, §72). No caso em questão, para que o Estado garantisse efetivamente o exercício do direito à liberdade de pensamento e de expressão do sr. Iribane, não bastava que fosse permitido que este escrevesse suas ideias e opiniões, mas, por sua vez, tal proteção compreendia no dever de não restringir sua difusão, de forma que se pudesse distribuir o livro, utilizando qualquer meio apropriado para fazer chegar tais ideias ao maior número de destinatários, e que esses pudessem receber tal informação (CORTE IDH, Iribarne vs. Chile, §73).

A Corte constatou que o Estado realizou os seguintes atos de controle ao exercício do direito do sr. Iribarne a difundir opiniões e ideias quando o livro "Ética e Serviços de Inteligência" se encontrava editado e em processo de publicação e comercialização: a proibição de publicar o livro (em aplicação ao art. 89 da Resolução da Marinha no 497); a ordem oral de retirar todos os livros existentes da editora (alegando de que afetavam a segurança e a defesa nacional); as apreensões feitas na casa do sr. Iribarne e na editora; as diligências com o propósito de recuperar diversos exemplares do livro que se encontravam em poder de varias pessoas e a ordem que proibia que o sr. Iribarne pudesse fazer comentários críticos sobre o processo, ao qual estava sendo submetido, ou sobre a imagem da Marinha. E, apesar do livro encontrar-se editado e com 1000 exemplares prontos, estes não puderem ser, efetivamente, difundidos em livrarias ou comércios do Chile, acarretando que a sociedade chilena não pudesse ter acesso ao seu conteúdo (CORTE IDH, Iribarne vs. Chile, §74).

O Tribunal considerou que é lógico que a formação e a experiência profissional militar do sr. Palamara Iribarne ajudou-o a escrever ao livro, sem que isso signifique, por si só, um abuso do exercício da sua liberdade de pensamento e expressão. Qualquer outra interpretação impediria que pessoas pudessem utilizar sua formação profissional ou intelectual para enriquecer suas ideias e opiniões (CORTE IDH, Iribarne vs. Chile, §76). Demais disso, a Corte IDH entendeu que os funcionários ou agentes de uma instituição devem manter a confidencialidade de certas informações, a que tenham acesso no exercício das suas funções, quando o conteúdo de tais informações é coberto por esse dever. O dever de sigilo não se estende às informações relativas à instituição ou as funções que desempenha quando versar sobre fato público. No entanto, em certos casos, a quebra de sigilo poderá resultar em 
responsabilidades administrativas, civis ou disciplinares. Neste caso, o conteúdo do dever de confidencialidade não é discutido, pois foi demonstrado que para escrever o livro "Ética e Serviços de Inteligência", o sr. Palamara Iribarne tinha usado informações de "fontes abertas" (CORTE IDH, Iribarne vs. Chile, §77).

Acerca das restrições à liberdade de expressão, através da imposição de responsabilidade ulterior do Tribunal de Justiça, é lógico e adequado que as declarações sobre funcionários públicos ou de outras pessoas que realizam os serviços públicos são oferecidas nos termos do artigo 13.2 da Convenção, maior proteção para permitir uma margem para amplo debate essencial para o funcionamento de um sistema verdadeiramente democrático.

Estes critérios são aplicados no presente caso, nas opiniões críticas ou declarações de interesse público feitas pelo Sr. Palamara Iribarne sobre as ações tomadas pelo Procurador Naval de Magallanes, no âmbito do processo penal militar contra ele instaurado, pelos crimes de desobediência e violação dos seus deveres militares. Além disso, os fatos deste caso e as declarações do Sr. Palamara Iribarne, despertaram o interesse da imprensa e, por consequência, do público (CORTE IDH, Iribarne vs. Chile, §82). Com efeito, o Tribunal considera que, neste caso, através da aplicação do delito de desacato, a persecução penal foi utilizada de maneira desproporcionada e desnecessária em uma sociedade democrática, a qual privou que o Sr. Palamara Iribarne exercesse o seu direito de Liberdade de Pensamento e Expressão, em relação aos pontos de vista críticos a respeito de assuntos que afetavam diretamente e possuem relação íntima com a forma que as autoridades da justiça militar cumpriam com as suas funções públicas, nos processos em que estava submetido.

Além disto, concluiu-se que as leis de desacato, aplicadas a Palamara Iribarne, estabeleceram sanções desproporcionais às críticas sobre o funcionamento das instituições do Estado e seus membros, removendo o debate essencial para o funcionamento de um sistema verdadeiramente democrático (CORTE IDH, Iribarne vs. Chile, §88).

Tratando-se de Palamara Iribarne, diferentemente do caso Ulloa e Canese, nos quais a Corte considerou não que as leis que versem sobre difamação e injúria sejam violadoras da Liberdade de Expressão, mas que, por sua vez, a aplicação foi dada de maneira desproporcional, na presente demanda temos notadamente a diferença, segundo o $\$ 95$ da sentença, qual seja:

95. (...) Além disso, ter incluído no seu regulamento jurídico interno, normas sobre desacato, contrárias ao artigo 13 da Convenção, algumas ainda em vigor, o Chile violou o dever geral de adotar disposições de direito interno estabelecidas no Artigo 2 da Convenção. 
Portanto, no caso em comento, houve uma violação da própria lei, do tipo penal. Isto é possível comprovar porque um dos pedidos manejados pela Corte IDH foi a de que o Estado derrogasse a lei de desacato, como um todo. Logo, é válido sublinhar o nuance que, à primeira vista, possa ser imperceptível, dado que a conclusão manejada é a de que o crime de desacato, per si, configura-se como plenamente incompatível com a Convenção Americana.

A demanda seguinte é, talvez, a mais emblemática e conhecida no sistema interamericano, é o caso Kimel vs. Argentina, cuja sentença data em 02 de maio de 2008. Segundo a demanda da Comissão, o senhor Eduardo Gabriel Kimel era um "conhecido jornalista, escritor e pesquisador histórico", que havia publicado vários livros relacionados à história política argentina, entre eles "O massacre de San Patricio", no qual expôs o resultado de sua investigação sobre o assassinato de cinco religiosos (CORTE IDH, Kimel vs. Argentina, §2).

O supramencionado livro criticava a atuação das autoridades encarregadas da investigação dos homicídios, entre elas um juiz de direito. Assim, em 28 de outubro de 1991, o Juiz mencionado pelo senhor Kimel promoveu uma queixa criminal contra ele pelo delito de calúnia, afirmando que, “apesar de a acusação desonrosa feita a um Magistrado por motivo ou ocasião do exercício de suas funções constituir desacato nos termos do art. 244 do Código Penal, hoje derrogado, a acusação específica referente a um delito de ação pública configura sempre calúnia” (CORTE IDH, Kimel vs. Argentina, §2). Dessa maneira, após a conclusão do processo penal, o senhor Kimel foi condenado pela Sala IV da Câmara de Apelações a um ano de prisão e a uma multa de vinte mil pesos pelo delito de calúnia (CORTE IDH, Kimel vs. Argentina, §2). Destarte, em função dos princípios não serem absolutos, estes são, por consequência, passíveis de restrições, como na aplicação de medidas ulteriores, no momento em que o exercício da Liberdade de Expressão viola direito de terceiros, in casu, supostamente, a honra alheia.

Todavia, para que se analise se a restrição atingiu o núcleo duro do direito humano previsto no art. 13, deve-se aplicar a limitação com especial cautela. Assim, como elucidado ao norte, o caso Kimel foi de extrema relevância para a fixação hermenêutica de quatro pontos cruciais, os quais devem ser salvaguardados para que se impeça a arbitrariedade. Logo, para que uma restrição da Liberdade de Expressão esteja em consonância com os padrões estabelecidos pela Corte IDH, deve-se analisar se a norma limitadora: i) respeita o princípio da legalidade estrita; ii) possui uma finalidade legítima; iii) é necessária; iv) está de acordo com a proporcionalidade estrita (CORTE IDH, Kimel vs. Argentina, §58).

i) Princípio da Legalidade estrita 
Segundo o entendimento do Tribunal, qualquer tipo de restrição ou limitação a direitos previstos da Convenção Americana, deve ser efetuado mediante norma legal. E, além disso, é obrigada a respeitar os limites tanto formais quanto materiais. No entanto, em se tratando da tipificação penal, esta deve ser: expressa, taxativa, precisa e prévia (CORTE IDH, Kimel vs. Argentina, §63), como demonstrado no excerto da decisão:

\begin{abstract}
63. A Corte entende que na elaboração dos tipos penais é preciso utilizar termos estritos e unívocos, que restrinjam claramente as condutas puníveis, dando pleno sentido ao princípio de legalidade penal. Este implica uma clara definição da conduta incriminada, que fixe seus elementos e permita distingui-las de comportamentos não puníveis ou condutas ilícitas sancionáveis com medidas não penais. A ambiguidade na formulação dos tipos penais gera dúvidas e abre espaço para o arbítrio da autoridade, particularmente indesejável quando se trata de estabelecer a responsabilidade penal dos indivíduos e sancioná-la com penas que afetam severamente bens fundamentais, como a vida ou a liberdade. Normas como as aplicadas no presente caso, que não delimitam estritamente as condutas delitivas, são violatórias do princípio de legalidade estabelecido no artigo 9 da Convenção Americana.
\end{abstract}

No caso concreto, o sr. Kimel foi condenado pela instância de piso pelo crime de injúria. Entretanto, o Tribunal de Apelações entendeu que se tratava de crime de calúnia. Portanto, a falta de precisão na normativa dos crimes demonstra a verdadeira arbitrariedade na aplicação da medida ulterior.

ii) Idoneidade e finalidade da restrição

O direito á honra, assegurado no art. 11 da Convenção Americana, assim como, o art. 13.2 prevê que a "reputação dos demais" pode ser um dos motivos para que haja restrição ao exercício da Liberdade de Expressão.

Dessa maneira, a reputação de toda pessoa é um fim legítimo e idôneo. Em vista disso, percebe-se que, de acordo com o entendimento da Corte no caso Kimel, a responsabilidade penal poderá ser aplicada, com o desiderato de proteger o bem jurídico em questão. Não obstante, isto não significa que o instrumento penal será necessário e proporcional em todos os casos de mesma natureza (CORTE IDH, Kimel vs. Argentina, §71).

iii) Necessidade da medida utilizada

Em casos anteriores, a Corte Interamericana já havia ratificado que o Direito Penal é o artifício mais restritivo e, por esse motivo deverá ser manejado, tão-somente, sob a estrita necessidade para proteger os bens jurídicos essenciais para uma sociedade (CORTE IDH, Kimel vs. Argentina, §76).

Além do exposto, faz-se crucial que a tipificação dos delitos de calúnia, injúria e difamação, não poderá ser ampla, a fim de que não sejam violados os princípios da Intervenção Mínima e de "ultimo ratio" do direito penal (CORTE IDH, Kimel vs. Argentina, 
§76). Assim, reafirma a Corte na sentença do caso Kimel:

77. Tomando em conta as considerações formuladas até agora sobre a proteção devida da liberdade de expressão, a razoável conciliação das exigências de tutela daquele direito, por uma parte, e da honra, por outra, e o princípio de mínima intervenção penal característico de uma sociedade democrática, o emprego da via penal deve corresponder à necessidade de tutelar bens jurídicos fundamentais diante de condutas que impliquem graves lesões a estes bens, e possuam relação com a magnitude do dano causado. A tipificação penal de uma conduta deve ser clara e precisa, como determinou a jurisprudência deste Tribunal no exame do artigo 9 da Convenção Americana.

Note que, em momento algum, o posicionamento da Corte IDH é o de proibir a aplicação da punição penal para salvaguardar a honra de terceiros. No entanto, apenas poderá ser utilizado em caráter de excepcionalidade, em casos de extrema necessidade e, além disso, a notória gravidade da conduta do indivíduo (emissor). Logo, um Estado democrático possui a incumbência de buscar um equilíbrio entre os dois direitos, consagrados no pacto americano de Direitos Humano, "sem debilitar as garantias que a livre expressão requer como sustentáculo do regime democrático” (CORTE IDH, Kimel vs. Argentina, §78).

iv) Estrita proporcionalidade da medida

A justa medida almejada seria a de satisfazer o direito à honra, sem que para isso, fosse restringido o direito de criticar a atuação de funcionários públicos (CORTE IDH, Kimel vs. Argentina, §84). Isto porque as atividades exercidas pelos mesmos não mais condizem à esfera privada, mas refletem no contexto público. Em consonância com esse entendimento, apreende-se que:

87. O controle democrático através da opinião pública fomenta a transparência das atividades estatais e promove a responsabilidade dos funcionários sobre sua gestão pública. Daí a maior tolerância diante de afirmações e apreciações expressadas pelos cidadãos no exercício deste controle democrático. Tais são as demandas do pluralismo próprio de uma sociedade democrática, que requer a maior circulação de informação e opiniões sobre assuntos de interesse público.

88. $\mathrm{Na}$ arena do debate sobre temas de alto interesse público, não apenas se protege a emissão de expressões inofensivas ou bem recebidas pela opinião pública, mas também das que chocam, irritam ou inquietam os funcionários públicos ou um setor qualquer da população. Em uma sociedade democrática, a imprensa deve informar amplamente sobre questões de interesse público, que afetam bens sociais, e os funcionários devem prestar contas de sua atuação no exercício de suas tarefas públicas.

Como alertado em linhas anteriores, quando se tratar de funcionário público e, portanto, de questões de interesse público, possuem uma esfera de proteção diferenciada, no exercício de suas funções, pois estão mais expostos ao escrutínio social, para que se possibilite o debate democrático (CORTE IDH, Kimel vs. Argentina, §86). Por fim, o posicionamento da Corte foi o de condenar o Estado da Argentina por violação ao direito à Liberdade de Expressão do sr. Kimel, em função das medidas utilizadas terem inibido, 
arbitrariamente, o exercício da garantia de manifestar-se sobre questões de relevante interesse social. Ademais, tais medidas foram desproporcionais, já que foram desmedidas, de acordo com a afetação do direito à honra supostamente violada de uma figura pública (CORTE IDH, Kimel vs. Argentina, §94).

O caso Tristán Donoso vs. Panamá, decidido em 27 de janeiro de 2009 incita novamente a controvérsia da aplicação de medidas ulteriores. Segundo a Comissão, a demanda se refere à "a interceptação, gravação e divulgação de uma conversa telefônica do advogado Santander Tristán Donoso com o seu cliente, demandada arbitrariamente por um ex-Procurador-geral da Nação; e a posterior abertura de um processo penal por delitos contra a honra como (suposta) represália às denúncias do senhor Tristán Donoso sobre a referida gravação e divulgação em uma conferência de imprensa; a falta de investigação e punição dos responsáveis por tais fatos, e a falta de reparação adequada" (CORTE IDH, Tristán Donoso, §). Assim, apesar de não ter sido aplicada a restrição de liberdade, já que a pena foi convertida ao pagamento de multa, a Corte IDH pacificou entendimento de que a sanção penal quedou-se desnecessária e incompatível com os parâmetros democráticos, independente da falta de reclusão. Portanto, por se tratar de funcionário público, como ressaltado nos casos anteriores, está passível a um maior escrutínio social.

Muito embora a sentença não tenha sido inovadora, quanto à ampliação dos argumentos utilizados, há dois aspectos bastante relevantes a ser sublinhado, o de que o sr. Donoso não fez uma opinião, mas uma afirmação dos fatos (CORTE IDH, Tristán Donoso, §124). Isto é, caracteriza-se como mera constatação dos fatos, alterando a esfera de proteção ante à Corte IDH, como se observa:

\footnotetext{
124. A Corte observa que a expressão feita pelo senhor Tristán Donoso não constituía uma opinião, mas uma afirmação de fatos. Enquanto as opiniões não são suscetíveis de serem verdadeiras ou falsas, as expressões sobre fatos sim o são. Em princípio, uma afirmação verdadeira sobre um fato no caso de um funcionário público em um tema de interesse publico será uma expressão protegida pela Convenção Americana. No entanto, a situação é distinta quando se está diante de um suposto de inexatidão fática da afirmação que se alega ser lesiva à honra.
}

Logo, a Corte a concluiu que "não era possível afirmar que sua expressão estivesse desprovida de fundamento, e que, consequentemente, fizesse do recurso penal uma via necessária.” (CORTE IDH, Tristán Donoso, §128). Demais disso, o caso Donoso foi crucial para fixar, mesmo de maneira tímida, o que seria interesse público no entendimento da Corte, conceito bastante utilizado em casos semelhantes, mas nunca delimitado. Transcrevendo in litis a passagem da sentença: 
146. A Corte considera de interesse púbico aquelas opiniões ou informações sobre assuntos no quais a sociedade tem um interesse legítimo de manter-se informada, de conhecer o que incide no funcionamento do Estado, que afeta direitos ou interesses gerais ou que acarretem consequências importantes.

Enfim, considera-se interesse público todos os assuntos que evolvam a participação da coletividade, ou seja, em que possa gerar efeitos para a sociedade. E, além do exposto, apreende-se que o acesso à informação para a construção de uma Democracia plena, está intimamente ligado a esta conceituação. Consequentemente, quando as alegações repercutirem socialmente, à medida que cerceá-la estará violando o Princípio da Liberdade de Expressão, em consonância com o caso concreto.

O próximo caso que versa sobre a aplicação de medidas ulteriores de forma desarrazoada é Usón Ramírez vs. Venezuela, sentenciado em 20 de novembro de 2009 pela Corte IDH, por unanimidade. Os fatos que circundam a demanda dizem respeito aos dias 16 de abril e 10 de maio de 2004, nos quais o senhor Usón Ramírez, militar reformado, havia sido convidado para participar de um programa de televisão chamado: “A Entrevista”. O tema do referido programa era as alegações feitas em artigo que estava sendo divulgado à época, de que as Forças Armadas estariam fazendo uso de um "lança-chamas", como meio de punição em Fort Mara, localidade na qual ocorreu um incêndio em 30 de março de 2004. Na oportunidade, o senhor Ramírez foi apresentado como um oficial de engenharia e, unicamente, no programa televisivo, o mesmo explicou como funcionava o instrumento e em quais hipóteses as Forças Armados o utilizavam. Por fim, ratificou que se as alegações fossem verdadeiras, esta seria uma situação bastante grave (CORTE IDH, Usón Ramírez vs. Venezuela, §38).

Desse modo, por haver feito tais declarações, o ex-militar foi julgado e condenado, no Tribunal Penal Militar, a cumprir a pena de cinco anos e seis meses de prisão, pela prática do delito de "injúria contra a Força Armada", por haver afirmado, em rede nacional, um fato falso (CORTE IDH, Usón Ramírez vs. Venezuela, §48) e por haver atentado contra a segurança nacional (CORTE IDH, Usón Ramírez vs. Venezuela, §51).

Destarte, o ponto mais relevante a ser suscitado no caso em comento é a de se as Forças Armadas enquadram-se nos ditames do art. 11 da Convenção, ou seja, debate-se sobre a alegada honra e reputação do supramencionado órgão. A Corte IDH valeu-se dos caracteres hermenêuticos presentes do caso Kimel, para solucionar a controvérsia. Inicialmente, ao debater o princípio da legalidade estrita, estabeleceu que o art. 505 do Código Militar venezuelano não delimitou o que significaria o crime de injúria, ofensa ou menosprezo. Assim, percebe-se que sua tipificação penal é ambígua e imprecisa, a qual gera dúvidas e abre 
o campo para o arbítrio da autoridade, especialmente quando estamos diante de um princípio de alta importância democrática como a liberdade (CORTE IDH, Usón Ramírez vs. Venezuela, §66).

Entretanto, quanto à idoneidade da medida, a Corte limitou-se a analisar se proteger o direito à honra era um fim legítimo ou não. Contudo, perdeu-se um bom momento para analisar a possibilidade de se saber se as Forças Armadas, ou qualquer outra pessoa jurídica, estariam abrangidas tanto pelo artigo 11 quanto no art. 13.2.

Todavia, a Corte concluiu que a norma penal militar que determinou a responsabilidade ulterior do sr. Ramírez, pelo exercício de sua Liberdade de Expressão, não era idônea, pelo fato de que, como no caso Kimel, a via do direito penal apenas será legítima, quando versar de bem jurídico hierarquicamente superior aos demais, que justifique a intervenção invasiva no Direito à Liberdade (CORTE IDH, Usón Ramírez vs. Venezuela, $\S 78)$.

A necessidade da medida, segundo entendimentos anteriores proferidos pela Corte, só será justificável quando o tipo penal for claro e isento de ambiguidade, estabelecendo quais as condutas que serão passíveis de punição. Portanto, apreende-se que no caso concreto inexistiu essa delimitação precisa, conferindo seu caráter arbitrário e desnecessário (CORTE IDH, Usón Ramírez vs. Venezuela, §85). Por fim, ao se discutir a proporcionalidade, a Corte entendeu que o processo penal, a privação preventiva de liberdade, a pena privativa de liberdade de 5 anos e 6 meses, a inscrição no registro de antecedentes criminais, o estigma por ter sido preso e por ter sido mantido longe do convívio com os seus familiares, demonstram que as medidas ulteriores estabelecidas, foram demasiadamente graves e incompatíveis com o ato praticado pelo r. Ramírez (CORTE IDH, Usón Ramírez vs. Venezuela, §91).

Ademais, reitera-se que por se tratar, indubitavelmente, de interesse público, o compromisso em informar à coletividade é ainda maior, contribuindo diretamente para a configuração do arbítrio praticado pelo Estado venezuelano (CORTE IDH, Usón Ramírez vs. Venezuela, §93).

\section{A POSIÇÃO DA COMISSÃO INTERAMERICANA DE DIREITOS HUMANOS ACERCA DA MATÉRIA}

Segundo a Comissão Interamericana de Direitos Humanos (CIDH) no seu Informe Anual de 1994, o crime de Desacato é incompatível com os parâmetros balizados na 
Convenção Americana, em especial com o direito da Liberdade de Expressão. O fato ilícito punível é a ameaça, ofensa ou insulto a um funcionário público no exercício de suas funções.

Dessa maneira, a recomendação dada pela CIDH é a de que os Estados-membros devem adequar suas legislações penais internas, derrogando as leis que preveem a criminalização dessa conduta. A justificativa exposta é a de que estas são inconciliáveis para o devido funcionamento de uma sociedade democrática.

Demais disso, a previsão de leis de desacato para resguardar a honra de funcionários públicos estipula um direito à proteção que os demais membros da sociedade não dispõem. Portanto, segundo esse posicionamento, “A CIDH concluiu que tais leis não são compatíveis com a Convenção porque se prestavam ao abuso como um meio para silenciar ideias e opiniões impopulares, reprimindo, desse modo, o debate que é crítico para o efetivo funcionamento das instituições democráticas" (CIDH, 1994). Por consequência, inibe-se ao direito dos cidadãos de criticar as ações e atitudes quanto à função pública.

Ademais, uma lei que ataque o discurso crítico contra a Administração Pública, tendo como objeto a pessoa que o emana, viola a essência e próprio conteúdo da Liberdade de Expressão, o qual se funda na possibilidade de expressar e compartilhar de pensamentos e informações.

Em razão do Desacato, inclusive como expressão de um juízo de valor ou uma opinião, de acordo com o Informe Anual de 1994 (CIDH, 1994), poderá:

(...) ser utilizado como método de suprimir a crítica e os adversários políticos. Mais além, ao proteger os funcionários públicos contra expressões difamantes, as leis de desacato estabelecem uma estrutura que, em última instância, protege o próprio governo de críticas.

Além do apresentado, por se tratarem de figura pública, deve-se ser aplicada uma proteção diferenciada de sua honra, pelo fato de atuarem em assuntos de interesse público, ou seja, que o efeito de suas ações recai sobre os demais cidadãos e suas decisões influem na coletividade, direta ou indiretamente. Nesse sentido, no supramencionado Informe (CIDH, 1994), demonstra-se:

A CIDH observa que contrariamente a estrutura que estabelecem as leis de desacato,
em uma sociedade democrática, as pessoas políticas e públicas devem estar mais
expostas - e não menos expostas - ao escrutínio e à crítica pública. A necessidade de
que exista um debate aberto e amplo, que é mais crucial para uma sociedade
democrática, deve abarcar necessariamente as pessoas que participam da formulação
ou aplicação da política pública. Dado que estas pessoas estão no centro do debate
público e se expõem ao escrutínio da cidadania, devem demonstrar mais tolerância à
crítica.

Finalmente, a conclusão da CIDH é a de que as leis de desacato não são necessárias para assegurar a ordem pública de uma sociedade democrática. Seu posicionamento funda-se 
no ideal de que a necessidade está ligada com o ideal de "necessidade social imperiosa" (CEDH, Sunday Times, §59), de maneira que os Estados não poderão invocar a manutenção da "ordem pública", de forma despótica, violando direitos civis primários. Assim, considerarse-ão tais medidas como desnecessárias e ilegítimas.

Ao se deparar com os demais tipos penais (calúnia, difamação e injúria), a CIDH considera que quando essas figuras são utilizadas para os mesmos fins do desacato, podem tornar-se demasiadamente perigosas para a ordem democrática. Assim, desde a perspectiva penal, o núcleo do desacato comporta a figura da calúnia e da difamação, mas dirigidas a um sujeito passivo específico. Destarte, a proteção da honra é considerada um fim legítimo. Entretanto, percebe-se a incidência de uma restrição indireta quando o Estado pune, por meio de uma sanção penal, expressões que versem sobre assuntos de interesse público, já que será considerada como uma resposta desproporcional aos anseios democráticos.

Desse modo, o esclarecimento feito pela CIDH é a de que a sanção penal de pessoas cujas alegações contribuam para o debate público, harmônico e necessário em uma sociedade, cuja democracia é o pilar desse sistema e na qual o acesso à informação é tão importante (senão mais) quanto à expressão de uma opinião individual, devem ser sumariamente retidas. Assim sendo, a recomendação da Comissão é de que haja, também, a adequação dos ilícitos penais dos crimes contra a Honra (em situações de interesse público), em função de estes serem confrontantes com o princípio da Liberdade de Expressão.

\section{CONCLUSÃO}

A Liberdade de Expressão é o direito cujo qual a Democracia não teria suporte algum, já que o debate público é o seu pressuposto. Ademais, apenas uma sociedade informada será capaz de ser plenamente livre. Por consequência, o acesso à informação é o elemento crucial para que haja a promoção desse caractere democrático.

As informações que possuem "interesse público geral”, segundo a Corte IDH, não são apenas aquelas que sejam pacíficas, mas que possam chocar, incomodar e espantar aos cidadãos. Assim, mais do que um direito, a Liberdade de Expressão, em sua esfera coletiva, é um dever. Todavia, apreende-se que, em regra geral, o exercício da Liberdade de Expressão pode encontrar entraves no direito à Honra, fixado no art.11, sendo plenamente possível (e de acordo com a Convenção Americana) a aplicação de medidas ulteriores, visto que nenhum direito é considerado absoluto. 
Assim, após a análise dos casos em questão, conclui-se que, em momento algum, a Corte IDH afirma que a sanção penal não pode ser instrumento de aplicação de uma medida ulterior. Todavia, esta deve ser manejada com especial cautela, com vistas de proteger os bens jurídicos mais importantes socialmente.

Contudo, quando se tratar de funcionários públicos, apesar de reconhecer que a proteção de sua honra é um motivo idôneo, a punição penal seria incompatível com os padrões de uma sociedade democrática, em função de que estes, quando estiverem no exercício de suas funções, estarem suscetíveis a um maior escrutínio público. Isto porque, segundo o entendimento da Corte, materializa-se o interesse público geral. Logo, possíveis incriminações são consideradas desproporcionais e desnecessárias.

Dessa maneira, percebe-se que o histórico jurisprudencial da Corte IDH é o de não permitir que opiniões que contribuam para o debate público (consequentemente que corroboram para a construção de uma sociedade democrática), sejam repelidas sem motivo algum. Portanto, o entendimento solidificado é o de que não se pode limitar o direito de promoção da informação social, por um arbítrio qualquer.

Note-se, ainda, que todas as pessoas que estavam no polo passivo dos procedimentos criminais eram pessoas públicas, no exercício de suas atribuições (diplomata, ex-presidente, as Forças Armadas, um juiz, Procurador da República), figura que possuem um grande valor social e as quais representam a própria figura de Estado. Apesar da consolidação de que o Direito Penal é um instrumento legítimo de repreensão, a tipificação penal deve ser clara, a fim de demonstrar qual o fato ilícito que será passível de sanção, a fim de rechaçar qualquer tipo de arbitrariedade por parte das autoridades públicas.

Demais disso, para que seja aceitável a limitação desse direito de especial relevância, a norma deve estar prevista em lei; seu fim deve ser idôneo; deve ser necessária e proporcional em uma sociedade democrática. Portanto, a Corte entende que em raríssimos casos sua supressão será justificável e plausível. Entretanto, isto é válido, tão-somente, para os crimes de calúnia, injúria e difamação, dado que quando estivermos diante do crime de desacato (o qual o polo passivo é justamente o funcionário público), conclui-se pela sua total incompatibilidade com a Convenção Americana, segundo o entendimento da Comissão Interamericana de Direitos Humanos (CIDH) e no caso Palamara Iribarne pela Corte IDH, em 2005.

\section{REFERÊNCIAS BIBLIOGRÁFICAS}


BERTONI, Eduardo Andrés. Libertad de expresión: debates, alcances y nueva agenda. Jurisprudencia interamericana sobre libertad de expresión avances y desafíos (p. 349-372). $3^{\mathrm{a}}$ ed. Cidade del México: D.R., 2011.

CIDH, Informe sobre la Compatibilidad entre las leyes de desacato y la Convención Americana sobre Derecho Humanos (1994). Disponível em: http://www.cidh.oas.org/annualrep/94span/cap.V.htm. Acesso em: 26/10/2014.

, Informe Anual 2000. Informe de la Relatoría Especial para la Libertad de Expresión. Capítulo II, Apend. B

Disponível

Marco juridico interamericano sobre el derecho a la libertad de expresión, 2010.

http://www.oas.org/es/cidh/expresion/docs/cd/sistema_interamericano_de_derechos_humanos /index_MJIAS.html. Acesso em: 10/09/2014.

CORREA, PALOMA MORAIS. A Soberania dos Estados no Sistema Interamericano de Direitos Humanos, 2010. UNIVERSIDADE DO RIO GRANDE DO SUL.

CORTE IDH. La colegiación obligatoria de periodistas (arts. 13 y 29 de la Convención Americana sobre Derechos Humanos), Opinión Consultiva 5/85 (en adelante OC-5 o La colegiación obligatoria) del 13 de noviembre de 1985, Serie A, No. 5.

ORGANIZAÇÃO DOS ESTADOS AMERICANOS. Convenção Americana sobre Direitos Humanos (Pacto de São José da Costa Rica), adotada em 22 de novembro de 1969.

SÁNCHEZ, Alfredo Chirino. Libertad de expresión: debates, alcances y nueva agenda. Libertad de Expresión y Ley Penal (p. 117-140). $1^{\text {a }}$ ed. Quito, Ecuador, 2011.

TORRIJO, Ximena Fuentes. La Proteccion de la Libertad de Expresion en el Sistema Interamericano de Derechos Humanos y la Promocion de la Democracia. Revista de Derecho, Vol. XIII, diciembre 2002, p. 225-244. Disponível em: http://mingaonline.uach.cl/pdf/revider/v13/art14.pdf. Acesso em: 09/09/2014.

\section{CASOS CONTENCIOSOS}

CORTE IDH. Caso Herrera Ulloa vs. Costa Rica. Excepciones Preliminares, Fondo, Reparaciones y Costas. Sentencia de 2 de julio de 2004. Serie C No. 107.

. Caso Kimel vs. Argentina. Fondo, Reparaciones y Costas. Sentencia de 2 de mayo de 2008 Serie C No. 177.

Caso Palamara Iribarne vs. Chile. Fondo, Reparaciones y Costas. Sentencia de 22 de noviembre de 2005. Serie C No. 135.

Caso Ricardo Canese vs. Paraguay. Fondo, Reparaciones y Costas. Sentencia de 31 de agosto de 2004. Serie C No. 111.

Caso Tristán Donoso vs. Panamá. Excepción Preliminar, Fondo, Reparaciones y Costas. Sentencia de 27 de enero de 2009 Serie C No. 193. 
Caso Usón Ramírez vs. Venezuela. Excepción Preliminar, Fondo, Reparaciones y Costas. Sentencia de 20 de noviembre de 2009. Serie C No. 207.

CORTE CEDH. The Sunday Times vs. United Kingdom, 26 de abril de 1979, Aplicação No 6538/74. 